\title{
1 Seed coating: science or marketing spin?
}

2 Simone Pedrini ${ }^{1,2 *}$, David J. Merritt ${ }^{2,3}$, Jason Stevens ${ }^{2,3}$, Kingsley Dixon ${ }^{1,3}$

3

$4 \quad{ }^{1}$ Department of Environment and Agriculture, Curtin University, Kent Street, Bentley, 6102, Western Australia

52 Kings Park and Botanic Garden, Fraser Avenue, Kings Park, 6005, Western Australia

$6{ }^{3}$ School of Plant Biology, The University of Western Australia, 35 Stirling Highway, Crawley WA 6009, Western 7 Australia.

8

$9 \quad *$ Correspondence: simone.pedrini@postgrad.curtin.edu.au

Keywords: Seed coating, polymers, protection, enhancement, marketing.

Abstract (max 120 words)

13 Seed coating is the practice of covering seeds with external materials to improve handling, protection and, to a lesser extent, germination enhancement and plant establishment. With an annual value exceeding one billion dollars, this technology is mostly the preserve of the private research sector, with few links to the scientific community. Here we analyse the science and industry of seed coating and its contribution to seed establishment and plant performance.

19 We posit that a closer collaboration between academia and industry is critical to realising the potential of seed coating both as a tool for enhancing plant establishment in the face of the challenges posed to agricultural systems and to propel the multi-billion-dollar global push for ecological restoration of degraded ecosystems. 


\section{What is seed coating and why is it done?}

2 Almost a century old [1], the practice of seed coating has become the mainstay for many of the world's horticultural and crop industries with a global value estimated at $\$ 53.76$

4 billion/year in 2014 i

5 Seed coating is the process of applying exogenous materials to the surface of the natural seed coat. This practice is used to modify the physical properties of seed [1,2], and for the delivery of active ingredients. The physical modification of seed aims to improve seed handling through standardization of seed weight and size [3]. In some cases, where the aim is to reduce friction and improve flowability, the alteration of seed morphology is minimal, but for small (e.g. begonia, tobacco), expensive, or morphologically uneven seeds, a thicker coverage is often applied. The artificial coat is frequently used as a carrier for a variety of active ingredients.

With the introduction of seed coating technology in developing countries, the global market for the materials alone (polymers, colourants and bulking agents) that are used in seed coating is expected to reach $\$ 1.63$ billion/year by 2020 ii.

Currently, seed coating is performed almost exclusively on crop and vegetable varieties and the application of this technology to wild plant species for ecological restoration, whose market is estimated at $\$ 18$ billion/year [4], has been rarely explored by the private companies involved in the development and application of seed coatings. (Suggested location for box 1)

The case for expanding seed coating technologies to wild species

Seed coating technologies have been developed on crop and vegetable species for the most part, and, to a lesser extent, on seeds of turf grass, pasture and flowers. The application of coatings to native species for ecological restoration has received little attention, with only sporadic evaluation in the scientific literature [5-7], and, so far, this field remains overlooked by the major agrochemical and seed technology companies. Yet seed is fundamental to environmental restoration and improved technologies for wild seed are necessary to meet global restoration targets such as the rehabilitation of 150 million ha of degraded land by 2020 - one of the United Nations sustainable development priorities iii. With the success rate of seedling establishment in restoration programs generally less than $10 \%[8,9]$ the scope for seed improvement of native plant species is vast. 
1 Seed coating technologies could be key to improving seedling establishment [10], plant

2 growth [6], and the restoration efficacy of native seed, most of which is collected from wild

3 sources and represents a finite resource not to be wasted [11].

4 If the UN goals for ecological restoration are to be met, it is time to forge enhanced links

5 between private and public seed technology research efforts. The development and

6 commercialization of seed coating solutions for the emerging restoration ecology market

7 could represent a major area of business for seed technology and agrochemical

8 corporations, improve their environmental credentials, and provide new opportunities to

9 deliver on their stated social obligations.

10 Equipment, materials and biological effects

11 It is common for studies of seed coating published in the scientific literature to have

12 outsourced the coating process to private seed companies (Box 2), meaning the specific details of the application technologies and materials are not disclosed.

14 (Suggested location for box 2)

15 These independent, academic seed coating studies use simplified small-scale approaches (e.g. laboratory mixers or shakers, manual coatings, seeds shaken in plastic bags, or experimental technologies such as liquid nitrogen [12], seed moulding [13], and seed extrusion [7]) in preference to the industrial standards (Key figure) (Supplemental Information, Figure S1 and S2). The dissimilarity in the equipment employed, and the difficulty in accessing information on materials and methods, are indications of the scarce transparency of industry. This lack of disclosure limits the capacity for independent scientific evaluation of the improvements delivered by seed coatings, and potentially compromises the critical analytical processes that could improve the understanding and adoption of seed enhancement technologies. Nevertheless, the materials used in the seed coating process can be broadly categorized according to their function as binders (see Glossary), fillers and active ingredients (box 1). Binders and fillers must be compatible with active compounds, and not adversely impact the ability of a seed to germinate and grow. According to the characteristics of the natural seed coat (testa), applied compounds can be dissolved and transmitted into the seed via imbibing water, or if the testa is impermeable to those substances, through the uptake by the emerging radicle and root system $[14,15]$. 


\section{Protectants}

2 The most commonly reported active ingredients in coatings include fungicides, pesticides,

3 insecticides, nematicides, predator deterrents and herbicides (box 3 ). The use of protectant

4 treatments at best only slightly promotes germination and emergence, and sometimes in

5 fact negatively affects the rate of germination [16]. However, protectant compounds do

6 usually benefit plant growth and yield through reducing predation and infection by

7 pathogens (supplemental information Figure S4).

8 Despite these benefits, sometimes the protectants employed in coating have negative off-

9 target environmental impacts. For example, neonicotinoids, the most widely employed insecticidal compounds [17] in crop seed coating, have been shown to cause a detrimental effect on wild bee diversity and distribution [18], with indirect impacts on honey bee health [19]. Moreover fungicidal and insecticidal coating products have indirect effects on the soil seed bank, potentially interfering with agroecosystem processes [20].

Further commitment is required by the agrochemical companies in developing new seed treatments to reduce off-target ecological impacts. Collaboration with the scientific community could help improve the testing of the efficacy of such products, and a broader ecological approach will allow for a more comprehensive assessment of potential biological impacts.

\section{Nutrients}

Where studies have evaluated nutrient amendments in seed coating, their effects on germination, growth, and yield are usually positive (Supplemental Information Figure S5). However, although the application of macronutrients like phosphorus [21] and potassium [22] improve growth and yield, there is the possibility of deleterious impacts on germination and emergence $[21,23]$ caused by nutrient-induced osmotic stress [24]. Most nutrient amendments have instead focused on the delivery of micronutrients such as zinc $[25,26]$, boron [27,28], molybdenum [29], copper [30,31] and manganese [32]. These amendments have been used to compensate for soil deficiencies in these trace elements [33]. The integration of seed biology, plant physiology, and soil science with a broader collaboration with the seed industry could optimize the use of seed coating as a way of delivering nutrients, ultimately allowing for the cultivation of varieties with predefined micronutrient requirements tailored to soil types with different trace elements deficiencies. 


\section{Symbionts}

2 The integration of symbiotic organisms into coating most commonly involves rhizobia for

3 the inoculation of legumes [34] leading to improvements in seedling growth and, to a lesser

4 extent, germination (Supplemental Information Figure S6). However, the incorporation of

5 inocula in an artificial seed coat can result in loss of microbial viability, with coated seeds

6 unable to be stored for extended periods [24].

7 The artificial seed coat is usually a hostile environment for the rhizobia, mostly due to

8 osmotic [35] and desiccation stress [36], and when protectant compounds are present, their biological activity could pose a threat to the survival of symbiotic bacteria [24]. The evaluation of more "rhizobia friendly" coating formulations, along with the selection of desiccation resistant bacteria, could improve symbiotic organism survival and the useful storage life.

\section{Soil adjuvants}

Soil hydrophilic materials or hydro absorbers (hydrogels) are the most commonly used compounds in seed coating for their inherent capability to attract and retain water in proximity to the seed [37-39]. Another strategy to increase water availability to seeds and seedlings in water repellent soil is to apply a soil surfactant within the seed coating material.[40,41].

Polymer coatings have also been used to delay germination through influencing water absorption, in a sense creating an artificial dormancy. This kind of coat inhibits germination when climatic conditions such as water availability are not optimal [42], usually providing protection from pathogens, fungi and predators [43]. This approach allows for early planting, relying on the coat to trigger the germination process when suitable conditions arise $[42,44,45]$ and thereby can improve seedling emergence in no-tillage soil [46]. The delay is usually achieved through temperature activated polymers that regulate water uptake at predefined temperature thresholds.

\section{Phytoactive promoters}

Phytoactive promoters comprise a range of compounds that, once incorporated into seed coatings, potentially stimulate germination, promote growth and improve stress resistance (Table 1).

(Suggested location for table 1) 
1 The limited number of promoters considered or disclosed in publications and in commercial

2 products show how those potentially highly beneficial compounds have been mostly

3 overlooked. However, the advantages of phytoactive compounds in the few cases where

4 they have been tested (Table 1), suggests potential benefits for large-scale improvement in

5 crop performance. Further investigations of these compounds are needed to better

6 understand the efficiency of delivery through the seed coat. The use of promoters has the

7 potential to improve: seedling and plant vigour; resistance to biotic/abiotic stresses;

8 performance under water, salinity, and temperature stress conditions. Innovation in the

9 deployment of phytoactive compounds via seed coats and pellets could be a key part of making farming possible in degraded areas or those areas adversely affected by climatic

11 change.

Tracers and colours

The incorporation of fluorescent dyes and magnetic powder into coating [47] has been developed to improve the traceability of seed batches through the supply chain, thereby limiting the risk of mislabelling and misplacement and allowing for the detection of counterfeit seed batches.

Colours are the most commonly employed amendment used in most seed coating processes (box 3). United States federal regulation of seed treatments iv mandates the use of artificial non-natural colours for seed treated with pesticide to highlight to seed-users the presence of harmful compounds and reduce the risk of inadvertent consumption. Moreover, colour in seed coating can help companies and users to differentiate seed of different origin, variety or treatment; it also facilitates the identification of seed in the field during sowing operations for ease of calibration of seeding equipment and for controlling seeding efficiency. Furthermore, the use of brightly coloured coats, in combination with layers of inert material and binders, has been found to limit the predation of corn seed by birds [48]. Notwithstanding these applications for the use of colour, there is a notably strong focus by industry on colour as an ingredient in coatings (Box 3); clearly the cosmetics of coatings $[30,49,50]$ provide a marketing boon for seed companies.

The market for coated seed

Though many private companies have been working on the improvement and commercialisation of seed coating technologies and coated seeds, much of the global 
market is nowadays controlled by six transnational agrochemical companies: Bayer Crop Science (Germany), Syngenta (Switzerland), Monsanto (USA), BASF (Germany), DuPontPioneer (USA) and Dow (USA). The core business, and research focus, of these enterprises lies mainly in the development of new plant varieties through breeding, genetic engineering and the improvement of chemical and biological protectants for seeds ${ }^{v}$. Seed coating technologies represent an effective means of applying these compounds onto selected seeds to combine the effect of genetically enhanced varieties with protectants. Smaller enterprises, such as Incotec (Netherland/United Kingdom) and Germains (United Kingdom) are dedicated to seed technology development and are major innovators in the seed coating market (Supplemental information Figure S7). They are specialised in the physicalmechanical aspects of seed coating with a focus on improving the retention of active ingredients, handling proprieties and the overall efficiency of seed delivery (sowing). However, the information provided by companies through websites, marketing campaigns, and press releases are not peer-reviewed nor independently tested and should, therefore, be considered carefully and critically.

(Suggested location for box 3)

\section{Marketing benefits}

Seed companies stress the importance of a coloured, coated seed as evidence of seed quality. End-users now expect their seed to be in a coloured and/or bulked state, and the supply of such seed is now the industry norm. Although the modification of seed size through encrusting and pelleting improves seed handling and allows for the application of more active ingredients, these build-up processes are portrayed almost universally by companies, and perceived by customers, as high-tech and somewhat crucial for enhancing seed establishment and plant performance. But the lack of independent testing to support these claims with respect to seed performance, and the difficulty in accessing company information on the pelleting processes and compositions, raises the question: Is all that inert material necessary? After all, the main goal of any commercial enterprise is to generate revenue, maximizing profit, and the exploitation of such a powerful marketing tool that is afforded by coating is understandably driven by market expectations. But to what degree do seed companies bulk seed to maximise profit, demanding premium prices for small amount of seeds pelleted in large quantities of relatively inexpensive, inert materials containing few active ingredients? 
1 The global seed market is progressing toward consolidation [51] with the merging of the major transnationals including the ongoing acquisition of Syngenta by ChemChina vi, and the take-over of Monsanto by Bayer vii. Such a trend increases the risk of oligopoly or even monopoly of the seed enhancement market with company behaviour no longer kept in check by the pressure of competitors [52].

Moreover, the many collaborations and connections recorded among companies [51] suggest that a similar scenario might already be unfolding, with trade secrets and trademark barriers in place to conceal technological know-how that might not be as advanced or effective as customers, and society in general, are bound to believe. This has important consequences if seed coating technology is to deliver the crop benefits for feeding an everincreasing global population, particularly in economically disadvantaged countries.

\section{Concluding remarks and future opportunities}

This critique is aimed at increasing the transparency of seed companies, in the hope that the very active (and well-funded) industry research departments will consider sharing and disclosing methodological and experimental results, to back up commercial claims with verifiable data and to promote the overall advancement of seed coating technologies. The research foci of academia and industry in this field have historically diverged, with private companies improving the mechanical proprieties of seed coatings, and the scientific community mostly focussed on evaluating the efficiency and impacts of active ingredients. Their integration could be highly beneficial for both the private sector and academia. For example, a recently developed framework for the analysis of wild seed recruitment identifies the critical plant life-stage transition(s) that contribute most to establishment failure [9]. This approach is a powerful tool that could be easily adapted to crop farming, directing seed coating solutions that maximise seedling establishment, plant growth, and yield.

The disclosure by industry of the innovative, and already optimised materials used in coating (in terms of mechanical performance) would allow researchers to improve seed coating in their area of expertise, rather than engaging significant effort in the fine-tuning of those materials and processes that have already been developed within the private sector. This could then increase the interest and engagement of the scientific community in seed coating technologies, resulting in more studies, publications and breakthroughs that could 
1 subsequently be adopted by industry. For example, further research and development of

2 the use ofphytoactive promoters in coating, largely over-looked to date, could improve seed

3 germination, seedling establishment, and stress resistance, potentially reducing the need for

4 environmentally harmful protectants and increasing food security in spite of the threats

5 posed by climate warming, pollution [53] and drought [54] to agricultural systems (see

6 Outstanding Questions).

7 The field of endeavour that could benefit the most from the application of coating

8 technologies is ecological restoration. At present seed availability, high cost [8] and low

9 seed establishment rate [4] represent serious limitations to the effective use of native seed.

10 Advanced seed technologies such as seed coating could be a key step in achieving cost-

11 effective ecosystem recovery at the planetary scale, while providing the benefit of new

12 business opportunities for seed companies. 


\section{BOX 1: Seed coating type and materials}

2 Seed coatings are categorized according to their physical characteristics. Although the nomenclature used in the literature is not consistent, the terminology most employed and recognized among industry and academia is based on the weight, size and sorting properties of the coated seeds. The basic coating treatment is film coating, where a thin layer of external material (usually less than $10 \%$ of seed weight) is applied. Where seed weight is increased up to $100-500 \%$ (depending on seed morphology), the procedure is described as encrusting, and is defined as such as long as the original shape of the seed is still evident $[55,56]$. Where the amount of external material makes it impossible to discriminate the initial seed shape (the result usually being a spherical shape), the process is named pelleting [50]. While film coated and encrusted seed are discerned by weight, pellets are sorted by diameter.

The structural materials employed in seed coating are categorized into binders and fillers. Binders are polymers of both natural and synthetic origin that provide adherence and cohesion of material onto the seed and the retention of active ingredients. They are usually applied in liquid form (in water or solvents), and when dried the dissolved monomers are rejoined in long polymeric chains forming a continuous film surrounding the seed, binding particles, and chemicals. Different layers of polymers can be applied at different stages of the coating process, some carrying treatments, and others providing a buffer to avoid direct contact between the "active layers" and the seed, the external environment, or other active layers.

In the majority of published scientific papers, seed coating has been undertaken with commercial binders of undisclosed composition. However, the most commonly reported binders are methylcellulose, polyethylene glycol, chitosan, polyvinyl alcohol, ethyl cellulose, polyvinyl acetate and gum arabic.

Pelleting and encrusting processes require the addition of a bulking agent that allows physical modification. This process is performed with either a single material, or a combination of multiple materials.

Fillers are usually inert powders like bentonite, calcium carbonate, talc, and diatomaceous earth, sand and wood dust (supplemental information Figure S2 and S3). 
1 The physical and chemical proprieties of the different powders, in combination with the

2 binders, provide a wide variety of possible mechanical and biological outcomes for coatings.

3 Particle size distribution Scott [24], for example, strongly affects the pellet behaviour; small particles provide higher physical resistance but limited gas and water exchange [57], whereas larger particles increase porosity, but reduce mechanical integrity and coat resilience.

\section{$8 \quad$ BOX 2: Seed coating equipment}

9 The rotating pan was the first machine employed for seed coating and derived from a patent lodged at the end of the $19^{\text {th }}$ century [58]. It is composed of a round pan, usually inclined, on a rotating motorised pivot. Seeds are placed inside the pan and while the pan is rotating, liquids are applied with a spray nozzle, and powders are applied through a hopper or by manual dusting. Rotating pans are mostly used to form pellets and rely on a slow rotating motion (5-35 rpm depending on diameter) [24] and the gradual addition of materials to increase pellet size [59]. The friction of seeds tumbling on each other is responsible for the spherical shapes produced and acts to smooth the external pellet surface. The process is followed by size-sorting with sieves, and then drying [56]. A low-cost alternative to the rotating pan used in some studies is a cement mixer [60]; this may have application in developing countries with limited resources.

The fluidised or spouted bed apparatus, originally conceived in 1970 for drying solids [61], was first adapted for seed coating in 1975 [62]. This apparatus is cylindrical, with seeds subjected to a constant sub-floor air flow that is adjusted to enable the seeds to remain buoyant in the air [56]. A spray nozzle atomizes the coating liquid or slurry towards the suspended seed mass. This process is used for film coating and superficial encrusting but is not feasible for pelleting.

A machine that allows for both film coating and pelleting is the rotary coater or rotor-stator. It is composed of a cylindrical drum, with a concave disk at the base, whose rotation causes the seed mass to move in a regular flow along the walls of the drum. A smaller rotating disk that is responsible for the atomization and projection of liquid or slurry to the rotating seed mass is usually attached to the drum lid and suspended in the middle of the drum $[3,7]$. 
1 These three systems are standard in the seed coating industry and are integrated into many seed treatment plants to allow for automated procedures and for continuous batch applications. Due to the high number of variables involved, including the material combinations, machine tuning, and seed morphological differences, it is not always feasible to rely entirely on automated systems and the "art and craft" of an experienced operator is often required to ensure the quality of the final product [56].

\section{BOX 3: Science and industry of seed coating active ingredients}

9 Using the last published major review on seed enhancement in 1998 [50] as the starting point, we analysed those publications examining seed coating technologies since that time, evaluating in all 145 refereed publications. With additional research into the web-published, trademarked and registered seed coating materials developed by the main agrochemical and seed technology companies, we identified 191 products that have been used in coatings. A comparison between the academic and industrial application of seed coating technologies shows some similarity in the kind of species tested; that is, mostly crop and vegetable varieties (Figure I). However, where the use of active ingredients has been reported, some differences between the public and private research sectors start to appear. Coating products employed by industry contain mostly colours and protectants, with limited records of the use of inoculants, nutrients, and phytoactive promoters.In contrast, published scientific literature reports mostly on protective compounds, with inoculants and other ingredients also commonly reported.

Moreover, the seed industry claims benefits of coatings focussed on those products that deliver cosmetic outcomes and enhanced mechanical proprieties, such as improving flowability and handling, product adherence, and reduction of the dust-off effect. This diverges from the academic research that concentrates mostly on the germination, emergence and growth responses of coated seeds. It is clear that the scientific and industrial research sectors have had limited interaction and that the development of coating technologies has followed separate paths. 
4 Key figure: Seed coating equipment and coat type produced.

5 The orange arrows on the equipment represent the motion of the moving components; the

6 equipment parts and arrows coloured in blue illustrate the method of delivery of the liquid 7 binding agent; and the gold arrows show where the fillers/powders are applied. Active 8 ingredients can be added either mixed with the liquid, with the powder, or independently. 9 The red arrows indicate which coatings can be achieved from each of the equipment types. 10 The weight of these red arrows represents the effectiveness of any particular machine for 11 producing the various types of coatings.

12 
' $\underline{\text { http://www.marketsandmarkets.com/PressReleases/seed.asp }}$

ii http://www.marketsandmarkets.com/Market-Reports/seed-coating-materials-market-

iii http://vote.riodialogues.org/

ivhttps://www.law.cornell.edu/cfr/text/40/153.155

${ }^{v} \underline{\text { http://news.agropages.com/News/NewsDetail---14163.htm }}$

vi http://www.reuters.com/article/us-syngenta-m-a-chemchina-idUSKCN12P186

vii http://www.bloomberg.com/news/articles/2016-09-14/bayer-clinches-monsanto-deal-

with-fourth-offer-of-66-billion

\section{References}

1 Kaufman, G. (1991) Seed Coating: A tool for stand establishment; a stimulus to seed

2 Avelar, S.A.G. et al. The use of film coating on the performance of treated corn seed. , Revista Brasileira de Sementes, 34. (2012) , 186-192

3 Halmer, P. (2008) Seed Technology and Seed Enhancement. Acta Hortic. 771, 17-26

4 Menz, M.H.M. et al. (2013) Hurdles and Opportunities for Landscape-Scale Restoration. Science (80-. ). 339, 526-527

5 Williams, M.I. et al. (2016) Can biochar be used as a seed coating to improve native plant germination and growth in arid conditions? J. Arid Environ. 125, 8-15

6 Madsen, M.D. et al. (2012) Agglomerating seeds to enhance native seedling emergence and growth. J. Appl. Ecol. 49, 431-438

7 Madsen, M.D. et al. (2014) Improving Restoration of Exotic Annual Grass-Invaded Rangelands Through Activated Carbon Seed Enhancement Technologies. Rangel. Ecol. Manag. 67, 61-67

8 Merritt, D.J. and Dixon, K.W. (2011) Restoration Seed Banks--A Matter of Scale. Science (80-. ). 332, 424-425

9 James, J.J. et al. (2011) Demographic processes limiting seedling recruitment in arid grassland restoration. J. Appl. Ecol. 48, 961-969

10 Liu, Y. et al. (2010) Effect of seed coating on plant growth and soil conditions: A preliminary study for restoration of degraded rangeland in the Qinghai-Tibetan Plateau, China. Grassl. Sci. 56, 145-152

11 Turner, S.R. et al. (2006) Influence of polymer seed coatings, soil raking, and time of sowing on seedling performance in post-mining restoration. Restor. Ecol. 14, 267-277

12 Pilar-Izquierdo, M.C. et al. (2012) Barley seed coating with free and immobilized alkaline phosphatase to improve P uptake and plant growth. J. Agric. Sci. 150, 691701

13 Sikhao, P. et al. (2015) Development of seed agglomeration technology using lettuce and tomato as model vegetable crop seeds. Sci. Hortic. (Amsterdam). 184, 85-92

14 Salanenka, Y.A. and Taylor, A.G. (2008) Seed Coat Permeability and Uptake of Applied Systemic Compounds. Acta Hortic. 782, 151-154 
15 Salanenka, Y. a. and Taylor, A.G. (2011) Seedcoat permeability: Uptake and postgermination transport of applied model tracer compounds. HortScience 46, 622-626

16 Yang, D. et al. (2014) Microencapsulation of seed-coating tebuconazole and its effects on physiology and biochemistry of maize seedlings. Colloids Surfaces B Biointerfaces 114, 241-246

17 Jeschke, P. et al. (2010) Overview of the Status and Global Strategy for Neonicotinoids (dagger). J. Agric. Food Chem. DOI: 10.1021/jf101303g

18 Rundlöf, M. et al. (2015) Seed coating with a neonicotinoid insecticide negatively affects wild bees. Nature 521, 77-80

19 Alburaki, M. et al. (2015) Neonicotinoid-Coated Zea mays Seeds Indirectly Affect Honeybee Performance and Pathogen Susceptibility in Field Trials. PLoS One 10, $\mathrm{e} 0125790$

20 Smith, R.G. et al. (2016) Evidence for indirect effects of pesticide seed treatments on weed seed banks in maize and soybean. Agric. Ecosyst. Environ. 216, 269-273

21 Peltonen-Sainio, P. et al. (2006) Phosphorus seed coating enhancement on early growth and yield components in oat. Agron. J. 98, 206-211

22 Tavares, L.C. et al. (2013) Potássio via recobrimento de sementes de soja: efeitos na qualidade fi siológica e no rendimento. Ciência Rural 43, 1196-1202

23 Mašauskas, V. et al. (2008) Phosphorus seed coating as starter fertilization for spring malting barley. Acta Agric. Scand. Sect. B - Plant Soil Sci. 58, 124-131

24 Scott, J.M. (1989) Seed coatings and treatments and their effects on plant establishment. Adv. Agron. 42, 43-83

25 Adhikari, T. et al. (2016) Zinc delivery to plants through seed coating with nano-zinc oxide particles. J. Plant Nutr. 39, 136-146

26 Oliveira, S. De et al. (2014) Tratamento de sementes de Avena sativa 1. com zinco: qualidade fisiológica e desempenho inicial de plantas. Semin. Ciências Agrárias 35, 1131

27 Rehman, A.U. and Farooq, M. (2013) Boron application through seed coating improves the water relations, panicle fertility, kernel yield, and biofortification of fine grain aromatic rice. Acta Physiol. Plant. 35, 411-418

28 Rehman, A.U. et al. (2012) Optimizing the Boron Seed Coating Treatments for Improving the Germination and Early Seedling Growth of Fine Grain Rice. Int. J. Agric. Biol. 14, 453-456

29 Hara, Y. (2013) Improvement of Rice Seedling Establishment in Sulfate-Applied Submerged Soil by Application of Molybdate. Plant Prod. Sci. 16, 61-68

30 John, S.S. et al. (2005) Seed Film Coating Technology for Maximizing the Growth and Productivity of Maize. Karnataka J. Agric. Sci. 18,

31 Wiatrak, P. (2013) Influence of seed coating with micronutrients on growth and yield of winter wheat in southeastern coastal plains. Am. J. Agric. Biol. Sci. 8, 230-238

32 Wiatrak, P. (2013) Effect of polymer seed coating with micronutrients on soybeans in southeastern coastal plains. Am. J. Agric. Biol. Sci. 8, 302-308

33 Farooq, M. et al. Micronutrient application through seed treatments: a review., Journal of soil science and plant nutrition, 12. (2012) , 125-142

34 Deaker, R. et al. (2004), Legume seed inoculation technology - A review. , in Soil Biology and Biochemistry, 36, pp. 1275-1288

35 John, R.P. et al. (2010) Development of emulsion from rhizobial fermented starch industry wastewater for application as Medicago sativa seed coat. Eng. Life Sci. 10, $248-256$

36 McIntyre, H.J. et al. (2007) Trehalose biosynthesis in Rhizobium leguminosarum by. trifolii and its role in desiccation tolerance. Appl. Environ. Microbiol. 73, 3984-3992 
Mangold, J.M. and Sheley, R.L. (2007) Effects of Soil Texture, Watering Frequency, and a Hydrogel on the Emergence and Survival of Coated and Uncoated Crested Wheatgrass Seeds. Ecol. Restor. 25, 6-11

38 Gorim, L. and Asch, F. (2012) Effects of Composition and Share of Seed Coatings on the Mobilization Efficiency of Cereal Seeds During Germination. J. Agron. Crop Sci. 198, 81-91

39 Serena, M. et al. (2012) Turfgrass Establishment from Polymer-coated Seed Under Saline Irrigation. HortScience 47, 1789-1794

40 Madsen, M.D. et al. (2013), Surfactant Seed Coating - a Strategy To Improve Turfgrass Establishment on Water Repellent Soils. , in International Symposium on Adjuvants for Agrochemicals, pp. 205-210

41 Honglu, X. and Guomei, X. (2008) Suspension Property of Gemini Surfactant in Seed Coating Agent. J. Dispers. Sci. Technol. 29, 496-501

42 Archer, D.W. and Gesch, R.W. (2003) Value of Temperature-Activated PolymerCoated Seed in the Northern Corn Belt. J. Agric. Appl. Econ. 35, 625-673

43 Johnson, G.A. et al. (1999), Use of temperature-responsive polymer seed coating to control seed germination. , in Acta Horticulturae, 504, pp. 229-236

44 Stokes, T. (2001) Coating enables early planting. Trends Plant Sci. 6, 243

45 Vyn, T.J. and Murua, M. (2001), Polymer Seed Coatings : Sufficient Risk Reduction for Early Plant Corn? , in 56th Annual Corn and Sorghum Research Conference., pp. $1-11$

46 Gesch, R.W. et al. (2012) Can using polymer-coated seed reduce the risk of poor soybean emergence in no-tillage soil? F. Crop. Res. 125, 109-116

47 Guan, Y. et al. (2013) The Novel Approach to Enhance Seed Security: Dual AntiCounterfeiting Methods Applied on Tobacco Pelleted Seeds. PLoS One 8, e57274

48 Almeida, A. De et al. (2010) Are camouflaged seeds less attacked by wild birds? Sci. Agric. 67, 170-175

49 Jamieson, G. (2008) NEW PERSPECTIVES ON SEED ENHANCEMENT. Acta Hortic. 782, 143-150

50 Taylor, a. G. et al. Seed enhancements. , Seed Science Research, 8. (1998) , 245-256

51 Howard, P.H. (2009) Visualizing consolidation in the global seed industry: 1996-2008. Sustainability 1, 1266-1287

52 Hannaford, S. (2007) Market Domination!: The Impact of Industry Consolidation on Competition, Innovation, and Consumer Choice,

53 Tai, A.P.K. et al. (2014) Threat to future global food security from climate change and ozone air pollution. Nat. Clim. Chang. 4, 817-821

54 Daryanto, S. et al. (2016) Global synthesis of drought effects on cereal, legume, tuber and root crops production: A review. Agric. Water Manag. DOI:

10.1016/j.agwat.2016.04.022

55 Gregg, B.B.R. and Billups, G. (2010) Seed coating and pelletizing. In Seed Conditioning, Volume 2 pp. 818-834, Science Publishers

56 Halmer, P. (2000) Commercial seed treatment technology. In Seed Technology and its biological basis (I. Black, M. and Bewley, J. D., eds), pp. 257-283, Sheffield Academic Press

57 Grellier, P. et al. (1999) Transfer and water-retention properties of seed-pelleting materials. Eur. J. Agron. 10, 57-65

58 William E. Upjohn (1885) Process of making pills US312041. , US312041

59 Scott, J.M. et al. (1997) The mechanics of coating seeds in a small rotating drum. Seed Sci. Technol. 25, 281-292

60 Hathcock, A.L. et al. (1984) Tall Fescue and Kentucky Bluegrass Response to 


\begin{tabular}{|c|c|}
\hline & tilizer and Lime Seed Coatings 1. Agranomy J.? \\
\hline 61 & Harkreader, G.G. (1970) Fluid bed drying system - US 3494046 A. , US 3494046 A \\
\hline 62 & $\begin{array}{l}\text { Hinkes, T.M. (1975) Seed coating process and product - US } 3911183 \text { A. , US3911183 } \\
\text { A }\end{array}$ \\
\hline 63 & $\begin{array}{l}\text { Guan, Y. et al. (2015) “On-Off” Thermoresponsive Coating Agent Containing } \\
\text { Salicylic Acid Applied to Maize Seeds for Chilling Tolerance. PLoS One 10, } \\
\text { e0120695 }\end{array}$ \\
\hline 64 & $\begin{array}{l}\text { Guan, Y. et al. (2014) An Enhanced Drought-Tolerant Method Using SA-Loaded } \\
\text { PAMPS Polymer Materials Applied on Tobacco Pelleted Seeds. Sci. World J. 2014, } 9\end{array}$ \\
\hline 65 & $\begin{array}{l}\text { Lizárraga-Paulín, E.-G. et al. (2013) Maize seed coatings and seedling sprayings with } \\
\text { chitosan and hydrogen peroxide: their influence on some phenological and } \\
\text { biochemical behaviors. J. Zhejiang Univ. Sci. B } 14,87-96\end{array}$ \\
\hline 66 & $\begin{array}{l}\text { Gevrek, M.N. et al. (2012) Growth and Yield Response of Rice ( Oryza sativa ) to } \\
\text { Different Seed Coating Agents. Int. J. Agric. Biol. } 14,826-830\end{array}$ \\
\hline 67 & $\begin{array}{l}\text { Richardson, M.D. and Hignight, K.W. (2010) Seedling emergence of tall fescue and } \\
\text { kentucky bluegrass, as affected by two seed coating techniques. Horttechnology } 20 \text {, } \\
415-417\end{array}$ \\
\hline 68 & $\begin{array}{l}\text { Zeng, D. and Shi, Y. (2009) Preparation and application of a novel environmentally } \\
\text { friendly organic seed coating for rice. J. Sci. Food Agric. 89, 2181-2185 }\end{array}$ \\
\hline 69 & $\begin{array}{l}\text { Diniz, K.A. et al. (2009) Sweet pepper seed responses to inoculation with } \\
\text { microorganisms and coating with micronutrients, aminoacids and plant growth } \\
\text { regulators, } 66\end{array}$ \\
\hline 70 & $\begin{array}{l}\text { ZHANG, H. et al. (2007) Effect and Mechanism of Cold Tolerant Seed-Coating } \\
\text { Agents on the Cold Tolerance of Early Indica Rice Seedlings. Agric. Sci. China } 6 \text {, } \\
\text { 792-801 }\end{array}$ \\
\hline 71 & $\begin{array}{l}\text { Diniz, K.A. et al. (2006) Incorporação de microrganismos, aminoácidos, } \\
\text { micronutrientes e reguladores de crescimento em sementes de alface pela técnica de } \\
\text { peliculização. Rev. Bras. Sementes } 28,37-43\end{array}$ \\
\hline 72 & $\begin{array}{l}\text { Tweddell, R.J. et al. (2000) A two-year field study of a commercial biostimulant } \\
\text { applied on maize as seed coating. Can. J. Plant Sci. 80, 805-807 }\end{array}$ \\
\hline
\end{tabular}

